University of Wollongong

Research Online

Faculty of Social Sciences - Papers (Archive) Faculty of Arts, Social Sciences \& Humanities

$1-1-2019$

Effects of steering locomotion and teleporting on cybersickness and presence in HMD-based virtual reality

Jeremy Clifton

University of Wollongong

Stephen Palmisano

University of Wollongong, stephenp@uow.edu.au

Follow this and additional works at: https://ro.uow.edu.au/sspapers

Part of the Education Commons, and the Social and Behavioral Sciences Commons

Research Online is the open access institutional repository for the University of Wollongong. For further information contact the UOW Library: research-pubs@uow.edu.au 


\title{
Effects of steering locomotion and teleporting on cybersickness and presence in HMD-based virtual reality
}

\author{
Abstract \\ While head-mounted display-based virtual reality (VR) can produce compelling feelings of presence (or \\ "being there") in its users, it also often induces motion sickness. This study compared the presence, \\ cybersickness and perceptions of self-motion (or "vection") induced when using two common methods of \\ virtual locomotion: steering locomotion and teleporting. In four trials, conducted over two separate days, \\ 25 participants repeatedly explored the "Red Fall" virtual environment in the game Nature Treks VR for 16 \\ $\mathrm{min}$ at a time. Although steering locomotion was found to be more sickening on average than teleporting, \\ 9 participants reported more severe sickness while teleporting. On checking their spontaneous postural \\ activity before entering VR, these "TELEsick" participants were found to differ from "STEERsick" \\ participants in terms of their positional variability when attempting to stand still. While cybersickness was \\ not altered by having the user stand or sit during gameplay, presence was enhanced by standing during \\ virtual locomotion. Cybersickness was found to increase with time in trial for both methods of virtual \\ locomotion. By contrast, presence only increased with time in trial during steering locomotion (it did not \\ vary over time when teleporting). Steering locomotion was also found to generate greater presence for \\ female, but not male, participants. While there was not a clear advantage for teleporting over steering \\ locomotion in terms of reducing cybersickness, we did find some evidence of the benefits of steering \\ locomotion for presence.

\section{Disciplines \\ Education | Social and Behavioral Sciences}

\section{Publication Details} \\ Clifton, J. \& Palmisano, S. (2019). Effects of steering locomotion and teleporting on cybersickness and \\ presence in HMD-based virtual reality. Virtual Reality: research, development and applications, Online First \\ $1-16$.
}




\title{
Effects of Steering Locomotion and Teleporting on Cybersickness and Presence in HMD-based Virtual Reality
}

\author{
Jeremy Clifton ${ }^{1}$ and Stephen Palmisano ${ }^{1 *}$
}

${ }^{1}$ School of Psychology, University of Wollongong, NSW, 2522, Australia.

\section{*Corresponding author:}

A/Prof Stephen Palmisano

School of Psychology,

University of Wollongong,

NSW, Australia, 2522

Email: stephenp@,uow.edu.au

Tel: (612) 4221-3640

Orcid ID: http://orcid.org/0000-0002-9140-5681

\begin{abstract}
While head-mounted display (HMD) based virtual reality (VR) can produce compelling feelings of presence (or "being there") in its users, it also often induces motion sickness. This study compared the presence, cybersickness and perceptions of self-motion (or "vection") induced when using two common methods of virtual locomotion: steering locomotion and teleporting. In four trials, conducted over two separate days, 25 participants repeatedly explored the "Red Fall" virtual environment in the game Nature Treks VR for 16-minutes at a time. Although steering locomotion was found to be more sickening on average than teleporting, 9 participants reported more severe sickness while teleporting. On checking their spontaneous postural activity before entering VR, these "TELEsick" participants were found to differ from "STEERsick" participants in terms of their positional variability when attempting to stand still. While cybersickness was not altered by having the user stand or sit during gameplay, presence was enhanced by standing during virtual locomotion. Cybersickness was found to increase with time in trial for both methods of virtual locomotion. By contrast, presence only increased with time in trial during steering locomotion (it did not vary over time when teleporting). Steering locomotion was also found to generate greater presence for female, but not male, participants. While there was not a clear advantage for teleporting over steering locomotion in terms of reducing cybersickness, we did find some evidence of the benefits of steering locomotion for presence.
\end{abstract}

Keywords: motion sickness; cybersickness; virtual reality; head-mounted display; presence. 


\title{
Effects of Steering Locomotion and Teleporting on Cybersickness and Presence in HMD-based Virtual Reality
}

\begin{abstract}
While head-mounted display (HMD) based virtual reality (VR) can produce compelling feelings of presence (or "being there") in its users, it also often induces motion sickness. This study compared the presence, cybersickness and perceptions of self-motion (or "vection") induced when using two common methods of virtual locomotion: steering locomotion and teleporting. In four trials, conducted over two separate days, 25 participants repeatedly explored the "Red Fall" virtual environment in the game Nature Treks VR for 16-minutes at a time. Although steering locomotion was found to be more sickening on average than teleporting, 9 participants reported more severe sickness while teleporting. On checking their spontaneous postural activity before entering VR, these "TELEsick" participants were found to differ from "STEERsick" participants in terms of their positional variability when attempting to stand still. While cybersickness was not altered by having the user stand or sit during gameplay, presence was enhanced by standing during virtual locomotion. Cybersickness was found to increase with time in trial for both methods of virtual locomotion. By contrast, presence only increased with time in trial during steering locomotion (it did not vary over time when teleporting). Steering locomotion was also found to generate greater presence for female, but not male, participants. While there was not a clear advantage for teleporting over steering locomotion in terms of reducing cybersickness, we did find some evidence of the benefits of steering locomotion for presence.
\end{abstract}

Keywords: motion sickness; cybersickness; virtual reality; head-mounted display; presence.

\section{INTRODUCTION}

With the release of more affordable, consumer-friendly head-mounted displays (HMDs), such as the Oculus Rift and the HTC Vive, virtual reality (VR) has received widespread interest in both the media and general population (Munafo et al. 2017). This technology provides the user with multi-modal, interactive sensory feedback which can generate an experience of being transported to a virtual world that feels real (Skarbez et al. 2017). Its ability to generate compelling feelings of presence (or "being there") distinguishes immersive VR from other contemporary forms of media and increases the extent to which the user responds realistically to the virtual environment (Cummings and Bailenson 2016; Schubert et al. 2001). For this reason, VR appears to be ideal for training individuals in tasks that are too difficult, dangerous, or expensive to be conducted in the real world (such as training military personnel and astronauts; Bhagat et al. 2016; Lawson 2015; Liu et al. 2016; Pedram et al. 2018). It has also been implemented effectively in psychological therapy to treat anxiety disorders, particularly phobias and posttraumatic stress disorder (Ling et al. 2014; Rothbaum et al. 2014).

Unfortunately, user experiences in VR are often undermined by the occurrence of motion sickness. Motion sickness during VR exposure is referred to as cybersickness (Rebenitsch and Owen 2016; Palmisano et al. 2017b). This cybersickness, which is commonly reported during (and in the hours following) immersive VR use, continues to limit its uptake by the mainstream population (Lackner 2014; Gavgani et al. 2017). As users play an active role in controlling the visual input in HMD-based VR, the provocative stimulation for their cybersickness is likely to be multi-sensory in origin (Palmisano et al. 2017b). Common symptoms of cybersickness include disorientation, dizziness, stomach awareness, headaches and, in severe cases, nausea (Lawson 2015). There can however be significant individual differences in cybersickness symptomology, with some users reporting no symptoms following exposure to a simulation that is highly nauseating for others (Keshavarz et al. 2015; Lawson 2015). Research has found that the severity of cybersickness increases with longer periods of exposure to HMD-based VR (Ruddle 2004). Several recent papers also report that women are more susceptible than men to both motion sickness and the cybersickness induced by HMDs (Allen et al. 2016; De Leo et al. 2014; Koslucher et al. 2015; Merhi et al. 2007; Munafo et al. 2017; Read and Bohr 2014). Although it should be noted that effects of biological sex are not always observed (see Keshavarz et al. 2018; Arcioni et al. 2018; Al Zayer et al. 2019; Gamito et al. 2008; Ling et al. 2013; Llorach et al. 2014). 


\subsection{Popular Explanations of Cybersickness}

Understanding the cause/s of cybersickness, is clearly the first step in preventing (or at least reducing) its occurrence. Sensory conflict remains the most common explanation of motion sickness in the literature (including cybersickness; Bles et al. 1998; Oman 1982; Reason and Brand 1975). According to sensory conflict (or sensory mismatch) theories, motion sickness occurs when information from our senses conflicts with either each other or with what is expected given the context. Sensory conflict due to vection (i.e., the illusion of self-motion) is often argued to be the prime cause of cybersickness - because the visual self-motion information should conflict with the information provided by the stationary user's other senses (see Hill and Howarth 2000; Keshavarz et al. 2015; Palmisano et al. 2011; Weech et al. 2018; Zacharias and Young 1981). Consistent with this proposal, a number of studies have found positive relationships between vection and visually induced motion sickness (Bonato et al. 2004, 2005, 2008; Diels et al. 2007; Flanagan et al. 2002; Nooij et al. 2017; Palmisano et al. 2007; Smart et al. 2002). However, other studies have reported negative or null relationships (Bonato et al. 2008; Ji et al. 2009; Golding et al. 2012; Keshavarz et al. 2014; Lawson 2005; Riecke and Jordan 2015; Webb and Griffin 2003). To date, the only two papers to have examined the relationship between vection and cybersickness during HMD-based VR found null (Palmisano et al. 2017a) or negative (Palmisano et al. 2017b) correlations between them.

Postural instability theory provides another popular alternative explanation of cybersickness. Riccio and Stoffregen (1991) define postural stability as a "state in which uncontrolled movements of the perception and action systems are minimized" (p. 202). They refer to uncontrolled movements as postural instability and argue that prolonged postural instability causes motion-sickness. According to their postural instability theory, motion sickness occurs in situations where an individual's mechanisms for maintaining postural stability are undermined. This theory predicts that: (1) experiences of motion sickness will always be preceded by increases in postural instability and persist until stability is restored; and (2) people who are more naturally unstable will be more likely to become motion sick during provocative stimulation (Stoffregen and Smart 1998). Its predictions are now supported by the findings of many studies on visually induced motion sickness (see Bonnet et al. 2006; Chang et al. 2012, 2013; Cook et al., 2018; Keshavarz et al. 2017; Koslucher et al. 2016; Merhi et al. 2007; Palmisano et al. 2017a; Smart et al. 2002, 2014; Stoffregen and Smart 1998; Stoffregen et al. 2000, 2008, 2010, 2014; Villard et al. 2008; Yokota et al. 2005). Two recent studies have also tested whether the theory generalizes to cybersickness experienced in HMD-based VR (Munafo et al. 2017; Arcioni et al. 2018). Consistent with its predictions, both studies found greater positional variability and different temporal dynamics in the sway of participants who later reported being sick.

\subsection{Types of Virtual Locomotion and Cybersickness}

Self-generated movements are crucial for exploring and interacting with the virtual environment (Steinicke et al. 2013). Locomotion through such environments can be produced by having the tracked user walk either small physical distances or on an omni-directional treadmill (Boletsis 2017; Langbehn et al. 2018; Llorach et al. 2014; Souman et al. 2011). However, due to limits in physical room space and hardware restrictions, most VR applications instead employ virtual locomotion, where the user remains relatively stationary and uses controllers to navigate their virtual environment (Boletsis 2017). While the particular virtual locomotion method that is chosen must allow effective exploration and interaction with the virtual environment, it also needs to generate minimal cybersickness.

The most common types of virtual locomotion are teleportation (where users indicate their desired destination and then are immediately transported to that location with a button press - Bozgeyikli et al. 2016; Boletsis 2017) and steering locomotion (where the user initiates a continuous simulated self-motion towards their desired destination using either joystick or pointing hand movements - Habgood et al. 2018). One major difference between them is that steering locomotion typically induces compelling vection (Palmisano et al. 2015). While steering locomotion continuously generates large areas of visual motion stimulation, such stimulation is dramatically reduced when using teleportation. This is the main reason why teleportation is assumed to be less provocative for cybersickness than steering methods (Steinicke et al. 2013). Consistent with this assumption, recent studies report that: 1) teleportation is more comfortable and generates less cybersickness than steering methods during HMDbased VR (Bozgeyikli et al. 2016; Christou and Aristidou 2017; Frommel et al. 2017; Habgood et al. 2018; Ragan 
et al. 2012; Vlahovic et al. 2018); and 2) variants of teleportation with animated transitions between locations are more provocative than traditional teleportation methods (which eliminate all visual motion information during these transitions - Rahimi et al. 2018). However, teleportation did not completely resolve the issue in these studies, as some users still reported cybersickness during teleportation and/or showed a clear preference for steering locomotion. This might have been because users had difficulties adjusting to their new surroundings after each teleportationbased displacement, and this led to disorientation (Ruddle et al. 2011; Freitag et al. 2014).

\subsection{Types of Virtual Locomotion and Presence}

Presence is one of the major benefits of HMD-based VR (see Skarbez et al. 2017). Thus, effective virtual locomotion should promote a strong experience of presence (Bowman et al. 1997). According to Slater (2009), presence depends on both: 1) the degree to which the user perceives that he/she is actually there in the virtual environment (referred to as the place illusion); 2) and the degree to which the user perceives that what is apparently happening is actually happening (referred to as the plausibility illusion). The place illusion is thought to increase with immersion (i.e., the extent to which the technology includes and surrounds the user's senses with a convincing environment and enables his/her valid actions - Slater and Wilbur 1997). By contrast, the plausibility illusion is thought to increase with the degree to which the user's interactions with the virtual environment are perceived to be consistent with their expectations (referred to as coherence - see Skarbez et al. 2017).

Arguably, the lack of continuous visual motion stimulation during teleportation, as well as the accompanying blinks in the visual scene, might weaken presence and alert users that they are in a virtual (as opposed to a real) environment (Slater and Steed 2000). As teleportation also involves non-ecological displacement from point $\mathrm{A}$ to $\mathrm{B}$, it has been proposed that it might be perceived as less coherent than steering locomotion (thereby reducing the plausibility illusion; Skarbez et al. 2017). Several studies have also found positive correlations between presence and vection (Keshavarz et al. 2018; Riecke et al. 2006), which suggests that presence should be greater during steering locomotion than teleporting (since only the former type of locomotion would be expected to induce compelling vection). Consistent with this notion, Vlahovic et al. (2018) found that steering locomotion produced greater presence than teleporting. However, a number of other studies failed to find significant differences between the effects of steering locomotion and teleporting on presence (Bozgeyikli et al. 2016; Frommel et al. 2017; Habgood et al. 2018). Most of these studies used rather simple virtual environments (designed to limit distraction and control experimental parameters). Thus, it is possible that their findings might not be representative of effects on presence in richer, more dynamic virtual environments (Bozgyikli et al. 2016; Habgood et al. 2018). To examine this possibility, the current study compared the effects of steering and teleportation locomotion on presence while playing Nature Treks VR - a commercial nature exploration game with large and detailed virtual environments.

\subsection{Relationship Between Cybersickness and Presence}

In a recent review, Weech and colleagues (2019) concluded that the available evidence favored a negative relationship between presence and cybersickness (i.e., feelings of presence decrease as cybersickness increases). However, past studies have reported positive (Wilson et al. 1997; Bangay and Preston 1998; Lin et al. 2002; Kim et al. 2005; Liu and Uang 2011; Ling et al. 2013), negative (Witmer et al. 1996; Wilson et al. 1997; Witmer and Singer 1998; Nichols et al. 2000; Kim et al. 2005; Knight and Arns 2006; Busscher et al. 2011; Milleville-Pennel and Charron 2015; Cooper et al. 2016) and neutral relationships between presence and cybersickness (Mania and Chalmers 2001; Seay et al. 2002; Robillard et al. 2003). Since these research findings are quite mixed, and only a subset of these past studies examined HMD-based VR, we plan to re-examine the relationship between presence and cybersickness in the current study.

\subsection{The Current Study}

Identifying an effective method of virtual locomotion to explore large simulated environments, which maximizes presence while mitigating the likelihood of cybersickness, remains a major challenge for VR developers (Steinicke et al. 2013). The current study examined the cybersickness and presence produced by two common methods of virtual locomotion. Our participants had to continuously navigate their way through a large simulated natural 
outdoor scene either by steering or teleporting. They performed both tasks in different trials either while seated or free-standing.

Based on sensory conflict theories, one might predict: 1) that cybersickness will be greater during steering locomotion than during teleporting (as continuous visual motion will only accompany the former, not the latter, type of virtual locomotion); and 2) a positive relationship between cybersickness and vection (as the continuous visual motion in the more provocative steering locomotion conditions would be expected to induce compelling vection, while teleporting conditions would not). We will test these predictions by measuring participants' vection strength ratings following each exposure to VR, as well as their ratings of cybersickness.

By contrast, postural instability theory predicts that participants who are more naturally unstable (i.e., before donning their HMDs) will be more likely to experience cybersickness. It is possible that these unstable participants may also be more likely to prefer teleporting over steering locomotion (compared to more stable participants, who should have less need of methods like teleporting, as they would be less likely to report cybersickness in general). If so, this could explain why most commercial VR applications provide more than one virtual locomotion technique. We will test these predictions by measuring each participant's spontaneous postural stability before each exposure to VR. Based on postural instability theory, we might also expect participants to be less likely to become motion sick when they are seated (as opposed to free-standing) during gameplay (consistent with past cybersickness findings by Merhi et al. 2007). Given previous findings (Munafo et al. 2017), we also predict that the incidence of cybersickness will be higher among females than males.

We also predict that steering locomotion will induce greater feelings of presence than teleporting (as the former condition is more ecological than the latter, and also provides continuous visual motion). In addition, as movements which are being simulated occur in the real world from a standing eye-height, being seated is expected to be perceived as less plausible during the virtual locomotion in Nature Treks VR, and therefore should reduce presence (Skarbez et al. 2017).

\section{METHOD}

\subsection{Design}

This experiment had a 2 (CONTROL TYPE: Steering or Teleporting) x 2 (POSTURE TYPE: standing or seated) x 6 (TIME IN TRIAL) within-subjects design. Each participant was tested over two days, completing two trials on each day. Sessions were separated by at least 24 hours to allow cybersickness symptoms to subside. As CONTROL TYPE was the primary variable of interest, exposure to each locomotion control type was counterbalanced across the two testing days. Presentation of each posture type was counterbalanced within each testing day. As several studies have reported that women appear to be more susceptible to cybersickness than men, we aimed for an even gender split in this study. The dependent variables recorded on each trial were: (1) the participant's history of gaming; (2) their spontaneous postural instability before VR exposure; (3) their cybersickness symptoms and sickness severity before, during and directly after VR exposure; (4) their feelings of presence during and directly after VR exposure; and (5) their overall experience of vection for each trial.

\subsection{Participants}

This study consisted of 25 adult participants (12 female and 13 male) ranging in age from $18-47$ years $(M=23.92$, $S D=5.25)$. Participants were recruited online from the general population. All had normal or corrected-to-normal vision with no self-reported visual, vestibular, or neurological impairments. Only 2 of our female participants reported playing video games regularly, compared to 10 of our male participants. It was confirmed that they were all feeling well at the start of each testing day. All of our participants were informed of the details of the study and provided us with written consent before the testing began. The University of Wollongong Human Research Ethics Committee approved the study in advance.

\subsection{Materials}


Each participant's spontaneous postural instability was first measured using a Bertec balance plate (http://bertec.com/products/legacy-balance-systems/). During the experiment, participants viewed the virtual environment through an HTC Vive HMD with stereo headphones attached (HTC, New Taipei City, Taiwan). The HTC Vive displays are dual AMOLED 3.6" diagonal screens with a resolution of $1080 \times 1200$ pixels per eye and a refresh rate of $90 \mathrm{~Hz}$. Participants were also equipped with two HTC Vive hand controllers. Tracking of the HMD and hand controllers was achieved via the Vive lighthouse system which uses two infrared base stations placed on opposite ends of the room. The experiment utilized Nature Treks VR software (http://greenergames.net/), downloaded from the Viveport VR app store. This game allows players to explore and shape different virtual environments by throwing creation orbs which produce a variety of plants where they land. Under guidance from their experimenter, participants explored "Red Fall", an autumn, sunny afternoon themed virtual environment. They navigated a circular route of lightly colored dirt paths around the exterior of this virtual environment. Nature Treks $V R$ has two main methods of virtual locomotion: 1) Steering: participants pointed with their left hand in their desired direction of travel while pressing the trigger on this hand remote. They were then simulated to walk in this pointing direction until the trigger was released; and 2) Teleporting: participants could alternatively press the trigger on the right hand remote to aim a target at a desired distant location in the virtual environment. Once they released the trigger, their (stereoscopic) point of view would immediately change to that location.

Cybersickness was measured in two different ways in this study. The Simulator Sickness Questionnaire (SSQ) was used to assess sickness symptomology directly before and after each exposure to VR (Kennedy et al. 1993). Participants had to rate 16 sickness symptoms from either $0=$ 'none', 1 = 'slight', 2 = 'moderate', or $3=$ 'severe'. In addition, during each exposure to VR, sickness severity was assessed every 3 minutes using the Fast Motion Sickness (FMS) scale (verbal ratings from 0 = 'no sickness' to 20 = 'frank sickness' - Keshavarz and Hecht 2011). A vection strength rating for each trial was also obtained (after completing the post-exposure items of the SSQ) using a 10 point scale from 0 (no vection/felt stationary) to 10 (strong, compelling vection). Presence was also measured in two different ways in this study. After each exposure to VR participants also completed the 14item Igroup Presence Questionnaire (IPQ) (Schubert et al. 2001). In addition, during each exposure to VR, an overall estimate of presence was obtained every 3 minutes using the following question, "To what extent do you feel present in the virtual environment, as if you were really there?" (from 0 to 10 as per Bouchard et al. 2004) ${ }^{1}$.

\subsection{Procedure}

Prior to the experiment, the participants' age, sex, height, video game usage, and previous VR experience were recorded. Participants were instructed to step onto the Bertec balance plate, positioned one meter from a blank wall, to measure their spontaneous postural instability (based on recorded fluctuations in their center of foot pressure (CoP)). Two 30 second sway samples were measured while they stood still and looked straight ahead at the blank wall with their hands clasped in front of them.

Participants were then given a brief two-minute introduction to Nature Treks VR and on how to use the Vive controllers. Directly before each trial, participants also completed the pre-exposure sections of the SSQ. They were told which locomotion type they would be using on that trial and whether they would be standing or sitting (in a rotating office chair with no arm rests) during that exposure to VR. After assisting them to don the HMD, the experimenter then positioned them in the center of the play area before the trial commenced.

Participants were required to navigate around a predetermined, circular route of the 'Red Fall' virtual environment in Nature Treks VR for 16 minutes (which involved both moving through the environment and completing the discrete tasks discussed below). During the steering trials, participants were instructed to continuously walk (minimizing their lateral movements). During the teleporting trials, participants were instructed to teleport every two seconds while maintaining a consistent intermediate teleporting distance (to limit their speed). To follow the predetermined route, participants had to slowly turn (completing a full rotation around every 6-7 minutes) by physically rotating (both when standing and when seated in the swivel chair). Throughout each trial, participants were prompted by the researcher to report their subjective levels of cybersickness (at $0,4,7,10,13$ and 16 minutes) and presence (at $0,3,6,9,12$, and 15 minutes). Every three minutes, participants were also asked to stop and create three plants of their choice (at 2, 5, 8, 11, and 14 minutes) using the game's creation orbs. This filler

\footnotetext{
${ }^{1}$ The authors acknowledge the limitations of subjective measures of presence. It is suggested that future studies utilize a combination of subjective and objective measures to examine this complex phenomenon.
} 
task was performed periodically to break up the long periods of navigation and took no longer than 30 seconds to complete each time. At the conclusion of each trial, participants immediately completed the post-exposure section of the SSQ, provided a rating of overall vection strength, and completed the IPQ. Between trials one and two, and trials three and four, participants were required to rest for a minimum of ten minutes to minimize the carryover of sickness symptoms.

\section{RESULTS}

Data from all 25 participants (12 females, 13 males) were included in the analyses. The cybersickness, presence and vection data will be reported and analyzed separately. Then we will examine the possible relationships between these different types of data.

\subsection{Cybersickness Data}

\subsubsection{Cybersickness Incidence and Symptomology}

Twenty-four of our 25 participants reported cybersickness during at least one of the experimental conditions: steering when standing (Steer/Stand), steering when seated (Steer/Sit), teleporting when standing (Teleport/Stand), and teleporting when seated (Teleport/Sit). We examined their post-exposure nausea (SSQ-N), disorientation (SSQD) and oculomotor (SSQ-O) symptoms after each of these four conditions. Overall, disorientation sub-scores $(M=$ 35.77) were found to be greater than the oculomotor sub-scores $(M=27.44)$ and nausea sub-scores $(M=21.66)$. This overall pattern (i.e. SSQ-D $>$ SSQ-O $>$ SSQ-N) can be seen in all 4 experimental conditions in Figure 1 . We also conducted separate 2 (CONTROL TYPE) x 2 (POSTURE TYPE) repeated measures ANOVAs on the postexposure SSQ-N, SSQ-O, and SSQ-D scores (to see if symptoms varied across the conditions as a function of these factors). However, none of the main effects or interactions were found to be significant for any of these analyses.

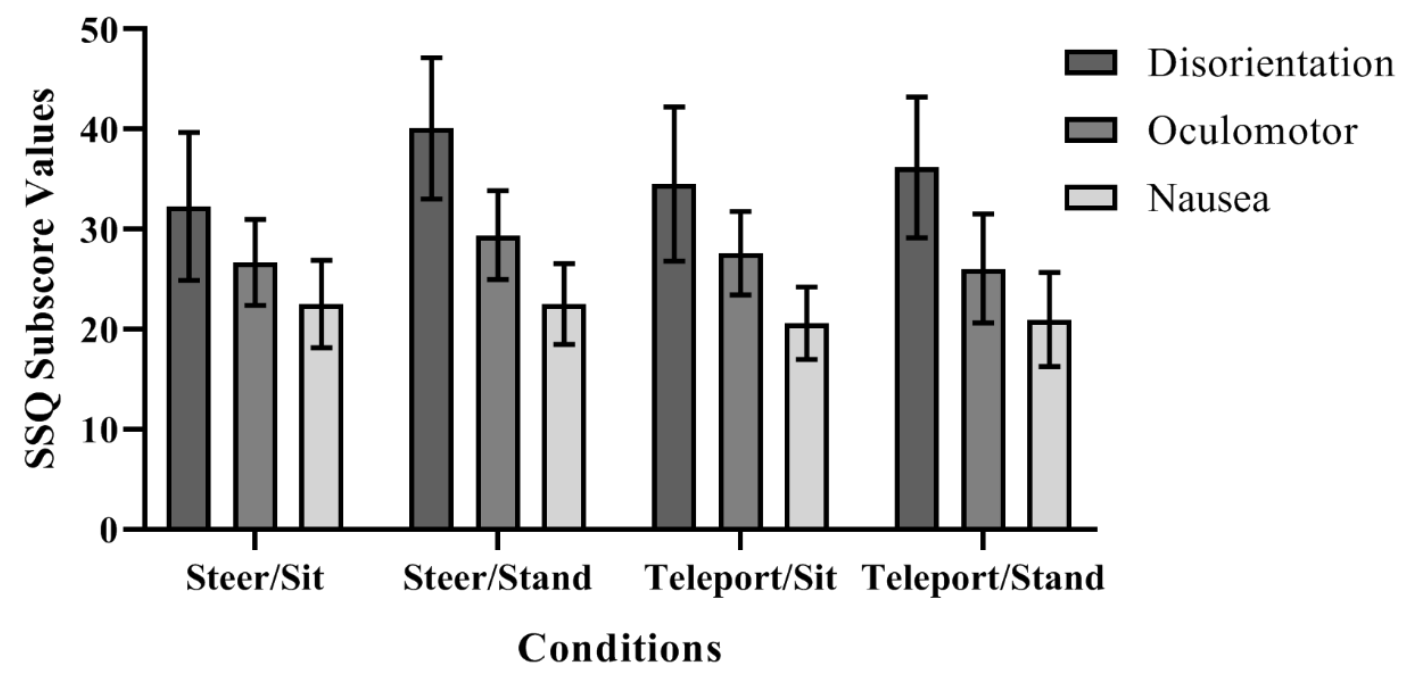

Fig 1. Mean SSQ sub-scores for nausea (SSQ-N), oculomotor (SSQ-O) and disorientation (SSQ-D) following each of the four experimental conditions (Steer/Stand, Steer/Sit, Teleport/Stand and Teleport/Sit). Higher scores indicate greater symptom severity. Error bars represent the standard error of the mean.

\subsubsection{Cybersickness Severity}

During each trial participants rated the severity of their sickness every 3 minutes from 0-20 using the FMS scale. To check for sickness contamination between the two trials tested on each day, and for evidence of carryover effects on cybersickness from testing day 1 to testing day 2, 3 paired samples t-tests were conducted. On day 1, the first FMS rating for trial 1 was found to be not significantly different to the first FMS rating for trial 2, $t(24)=-2.030$, 
$p>0.05$. On day 2, the first FMS rating for trial 3 was also not found to be significantly different to the first FMS rating for trial 4 (i.e., both of the trials on day 2 ), $t(24)=1.495, p>0.05$. Finally, across the two days, the first FMS rating for trial 1 was not significantly different to the first FMS rating for trial $3, t(24)=-1.830, p>0.05$. These findings suggest that there was not significant contamination across trials within each testing day and that participants were initially well on both testing days.

\subsubsection{Effects of SEX, CONTROL TYPE, POSTURE TYPE, and TIME IN TRIAL on Cybersickness Severity}

We next conducted a 2 (SEX) x 2 (CONTROL TYPE) x 2 (POSTURE TYPE) x 6 (TIME IN TRIAL) mixed model ANOVA to examine these FMS scores (see Figure 2). The main effect of CONTROL TYPE was found to be significant, $F(1,23)=5.196, p=.03, \eta_{\mathrm{p}}{ }^{2}=.184$-indicating that on average steering induced greater cybersickness $(M=2.970, S E=.625)$ than teleporting $(M=2.064, S E=.450)$. The main effect of TIME IN TRIAL was also found to be significant for FMS scores, $F(1.7,39.27)=17.817, p<.001, \eta_{\mathrm{p}}{ }^{2}=.437$. As can be seen in Figure 2, cybersickness increased with TIME IN TRIAL for all four conditions. However, the main effect of POSTURE TYPE was not significant for these FMS scores, $F(1,23)=.232, p=.635, \eta_{\mathrm{p}}{ }^{2}=.010$. The main effect of SEX was also not significant, $F(1,23)=.430, p=.518, \eta_{\mathrm{p}}{ }^{2}=.018$. None of the interactions were found to be significant for FMS scores.

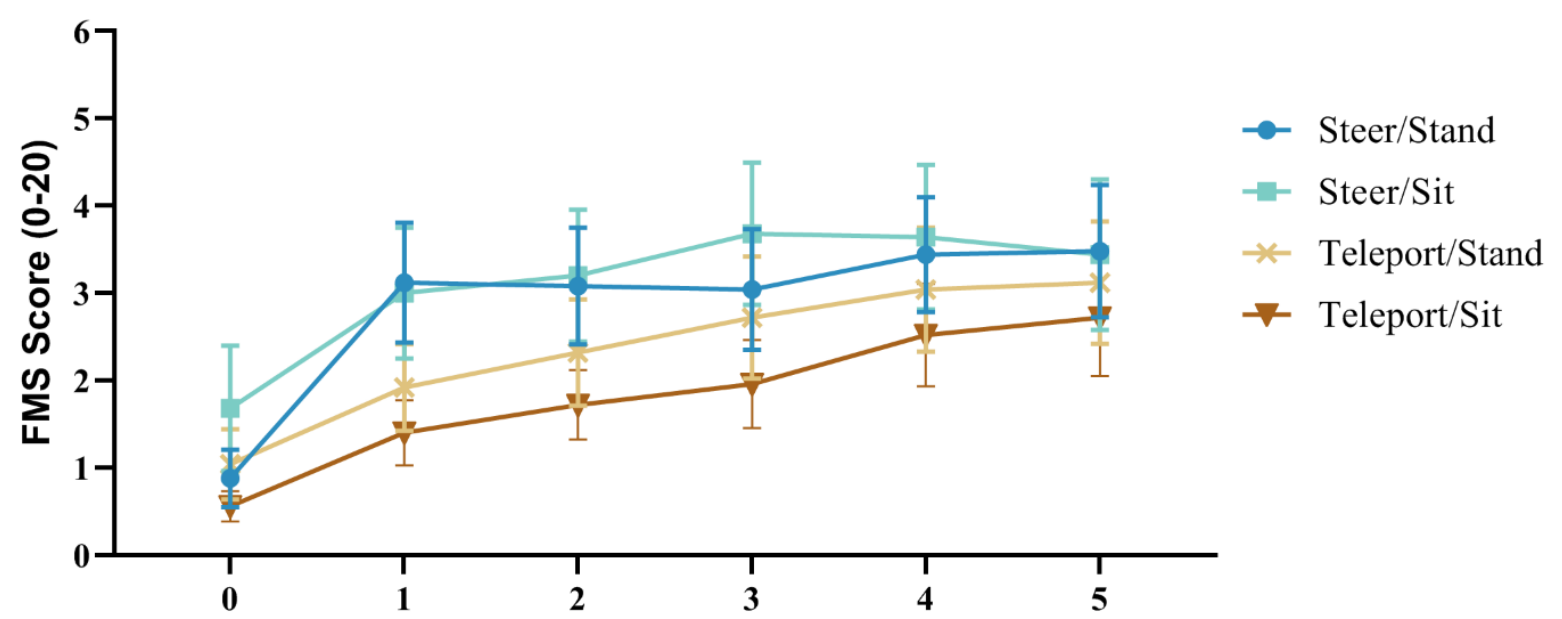

Response Number in Trial

Fig 2. Mean FMS scores for the four different conditions (Steer/Stand, Steer/Sit, Teleport/Stand and Teleport/Sit) across the six different response intervals in each trial (these intervals were 3 minutes apart). Error bars represent the standard error of the mean.

\subsubsection{Relationships between Cybersickness and Spontaneous Postural Activity}

We had originally planned to examine whether individual differences in participants' spontaneous postural instability could be used to predict who would become sick and who would remain well in HMD-based VR. However, as all but one of our 25 participants reported feeling sick, it was not possible to investigate this specific hypothesis. We had also hypothesized that more unstable participants might be more likely to prefer teleporting over steering locomotion. While cybersickness severity was on average greater for the steering conditions, a significant proportion of our participants were found to have higher FMS ratings for the teleporting conditions. Participants were thus split into "STEERsick" and "TELEsick" groups, based on whether they had higher FMS ratings for their steering or their teleporting conditions. There were 15 participants in the "STEERsick" group and 9 in the "TELEsick" group respectively. We then examined whether participants in these two groups differed in terms of their spontaneous postural activity (measured as 30-second recordings of their CoP fluctuations when they were standing quietly before VR exposure). This CoP time series data was first smoothed, using a low-pass order5 Butterworth filter and a cut-off frequency of $10 \mathrm{~Hz}$. Then each participant's positional variability was estimated by calculating the standard deviation of his/her COP data along the anterior-posterior $(\mathrm{A} / \mathrm{P})$ and the medial-lateral 
$(\mathrm{M} / \mathrm{L})$ axes. The temporal dynamics of this spontaneous postural activity was next examined by conducting detrended fluctuation analyses (DFAs) on the COP data for each axis. We calculated the scaling exponent of the DFA (i.e., $\alpha$ ), which indexes long range autocorrelation in the CoP data (Chang et al. 2013). Average standard deviations of the CoP (STDEV CoP) and DFA $\alpha$ values were calculated separately for the medio/lateral (M/L) and anterior/posterior (A/P) axes. Then separate independent samples $t$-tests were conducted on each of the sway indices.

We found that STDEV CoP $\operatorname{Col}_{\mathrm{L}}$ values were significantly greater for the "TELEsick" group $(M=.002 \mathrm{~m}$, $S E=.0004 \mathrm{~m})$ than the "STEERsick" group $(M=.001 \mathrm{~m}, S E=.0001 \mathrm{~m}), t(22)=2.558, p=.018$, two-tailed, $d$ $=.95$ (Figure 3 right). Differences in DFA $\alpha_{\mathrm{M} / \mathrm{L}}$ between these two groups also approached significance, with the values for the "TELEsick" group $(M=1.517, S E=.025)$ being larger than those for the "STEERsick" group $(M=$ $1.442, S E=.023), t(22)=2.119, p=.046$, two-tailed, $d=1.07$. However, there were no significant differences between the two groups in terms of either $\mathrm{STDEV} \mathrm{CoP}_{\mathrm{A} / \mathrm{P}}, t(22)=.091, p=.928$, two-tailed, $d=.09$ (Figure 3 left), or their DFA $\alpha_{\mathrm{A} / \mathrm{P}}$ values, $t(22)=.127, p=.900$, two-tailed, $d=.05$.

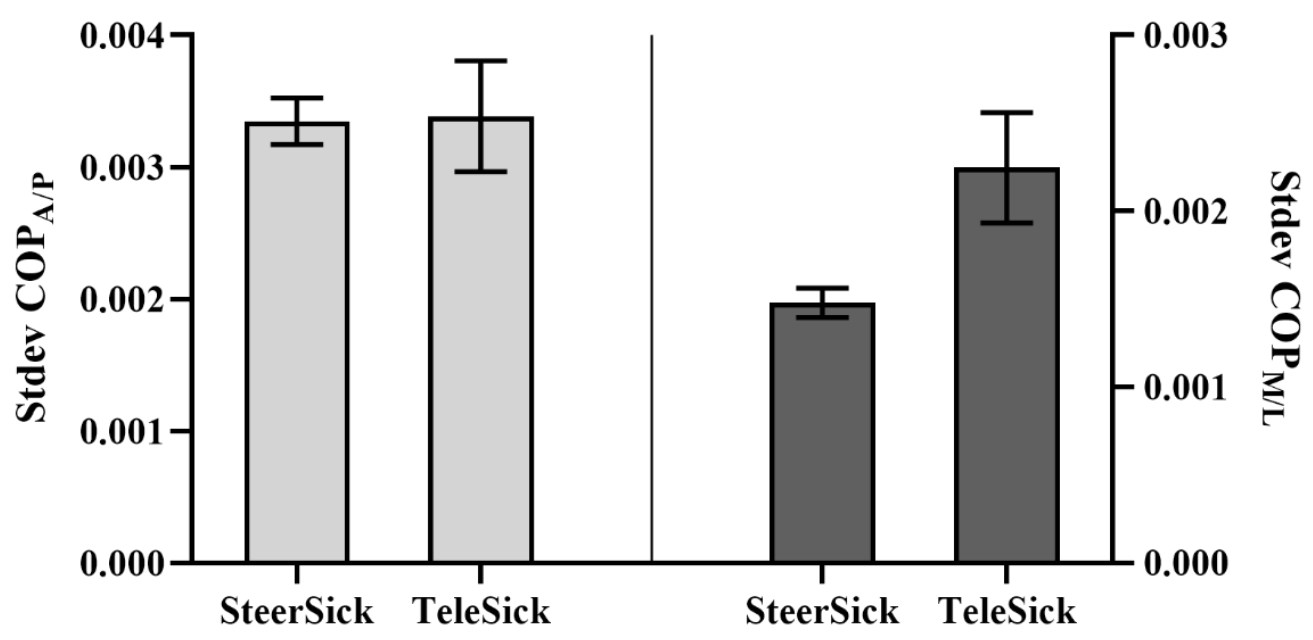

Fig 3. Differences in standard deviations of CoP position between "TELEsick" and "STEERsick" along the anterior/posterior (A/P; left) and medio/lateral (M/L; right) axes. Error bars represent the standard error of the mean.

\subsection{Presence Data}

\subsubsection{IPQ subscale data}

Using the IPQ, we examined spatial presence, involvement and experienced realism for each of the four experimental conditions (see Figure 4). Separate 2 (CONTROL TYPE) x 2 (POSTURE TYPE) repeated measures ANOVAs were conducted on each of the sub-scores of the IPQ. Results revealed that steering locomotion $(M=$ $3.832, S E=.171)$ produced significantly more spatial presence than teleporting $(M=3.324, S E=.219), F(1,24)=$ $4.753, p=.039, \eta_{\mathrm{p}}{ }^{2}=.165$. Experienced realism was also greater during steering locomotion $(M=2.575, S E=.212)$ than teleporting $(M=2.085, S E=.183), F(1,24)=8.765, p=.007, \eta_{\mathrm{p}}{ }^{2}=.268$. Standing $(M=2.440, S E=.193)$ also produced greater experienced realism than sitting $(M=2.220, S E=.180), F(1,24)=4.910, p=.036, \eta_{\mathrm{p}}{ }^{2}=.170$. No other significant main effects or interactions were observed in these analyses. 


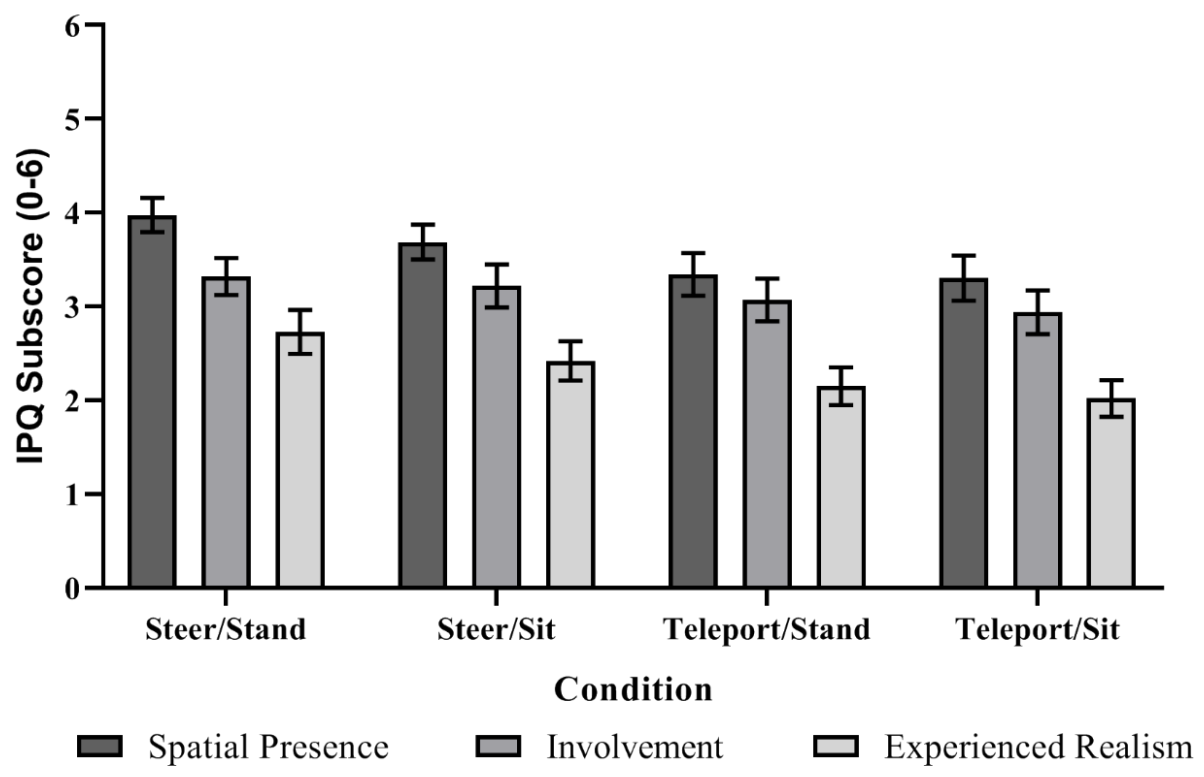

Fig 4. Mean IPQ sub-scores for spatial presence, involvement and experienced realism across each of the four conditions (Steer/Stand, Steer/Sit, Teleport/Stand and Teleport/Sit). Error bars represent the standard error of the mean.

\subsubsection{Effects of SEX, CONTROL TYPE, POSTURE TYPE, and TIME IN TRIAL on overall Presence}

During each trial participants verbally rated their overall feelings of presence every 3 minutes from $0-10$. We conducted a 2 (SEX) x 2 (CONTROL TYPE) x 2 (POSTURE TYPE) x 6 (TIME IN TRIAL) mixed model ANOVA to examine these verbal presence ratings. The interaction between SEX and CONTROL TYPE was found to be significant, $F(1,23)=4.707, p=.041, \eta_{\mathrm{p}}{ }^{2}=.170$ (see Figure 5). Simple main effects determined that presence did not significantly differ for males based on CONTROL TYPE, $F(1,12)=.022, p=.885, \eta_{\mathrm{p}}{ }^{2}=.002$. However, for females, steering locomotion $(M=7.507, S E=.382)$ produced significantly greater ratings of presence than teleporting $(M=6.250, S E=.448), F(1,11)=14.994, p=.003, \eta_{\mathrm{p}}{ }^{2}=.577$. The CONTROL TYPE by TIME IN TRIAL interaction was also found to be significant, $F(2.228,51.238)=5.207, p=.007, \eta_{\mathrm{p}}{ }^{2}=.185$ (see Figure 6). Therefore, simple main effects were run. The effect of TIME IN TRIAL was not statistically significant in the teleporting condition, $F(1.523,36.553)=2.070, p=.15, \eta_{\mathrm{p}}{ }^{2}=.079$. TIME IN TRIAL was however found to be significant in the steering locomotion condition, $F(1.755,42.115)=8.579, p=.001, \eta_{\mathrm{p}}{ }^{2}=.263$. As can be seen in Figure 6, mean presence ratings tended to increase over time and stay high during steering locomotion trials. By contrast, in teleporting trials, presence ratings appeared to increase initially but then later decreased over time. The ANOVA also found a significant main effect of POSTURE TYPE, $F(1,23)=8.303, p=.008, \eta_{\mathrm{p}}{ }^{2}=.265$, where standing $(M=6.590, S E=.270)$ induced higher levels of presence than sitting $(M=6.154, S E=.343)$. No other interaction effects were found to be significant. 


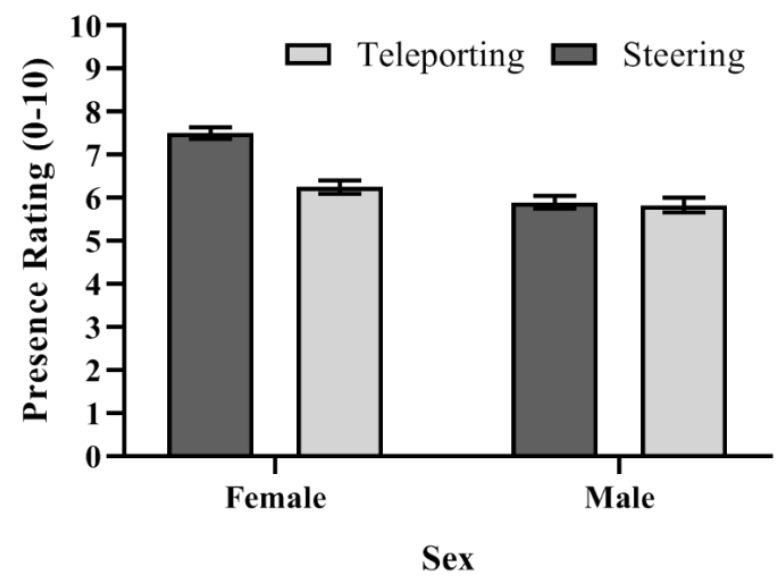

Fig 5. Mean presence ratings for males and females during steering locomotion and teleporting conditions. Error bars represent the standard error of the mean.

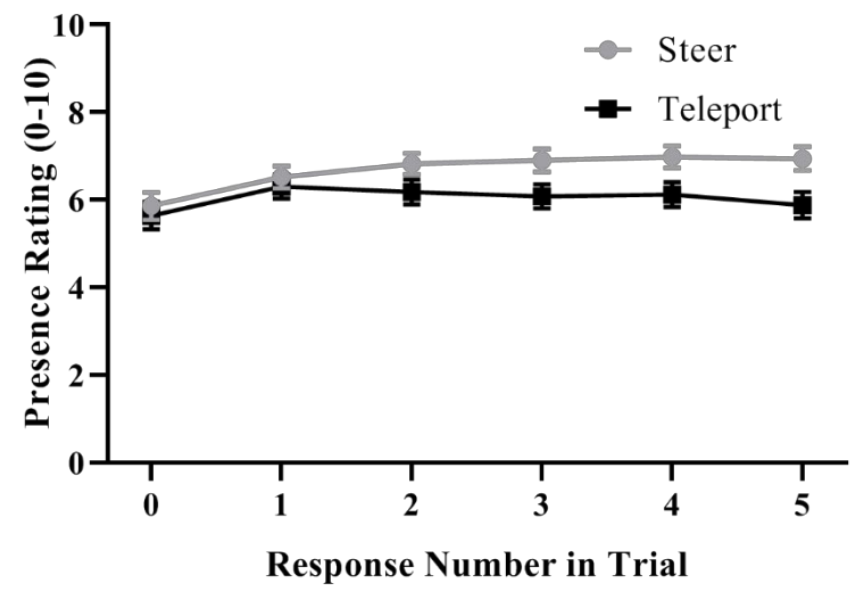

Fig 6. Mean presence ratings for steering locomotion and teleporting conditions across the 6 different response intervals in these trials. Error bars represent the standard error of the mean.

\subsection{Vection Data}

An overall rating of vection strength was obtained for each condition directly after each trial. We conducted a 2 (SEX) x 2 (CONTROL TYPE) x 2 (POSTURE TYPE) mixed model ANOVA to examine these vection strength ratings. We found significant main effects of CONTROL TYPE, $F(1,23)=44.535, p=.000, \eta_{p}{ }^{2}=.659$, and POSTURE TYPE, $F(1,23)=7.268, p=.013, \eta_{p}{ }^{2}=.240$ (see Figure 7). Vection was strongest during steering locomotion $(M=6.250, S E=.366)$ compared to teleporting $(M=3.641, S E=.401)$, and whilst standing $(M=5.239$, $S E=.349)$ compared to sitting $(M=4.652, S E=.346)$. The main effect of participant SEX was not significant, $F$ $(1,23)=1.377, p=.253, \eta_{p}{ }^{2}=.057$. None of the 2- or 3-way interactions were found to be significant. 


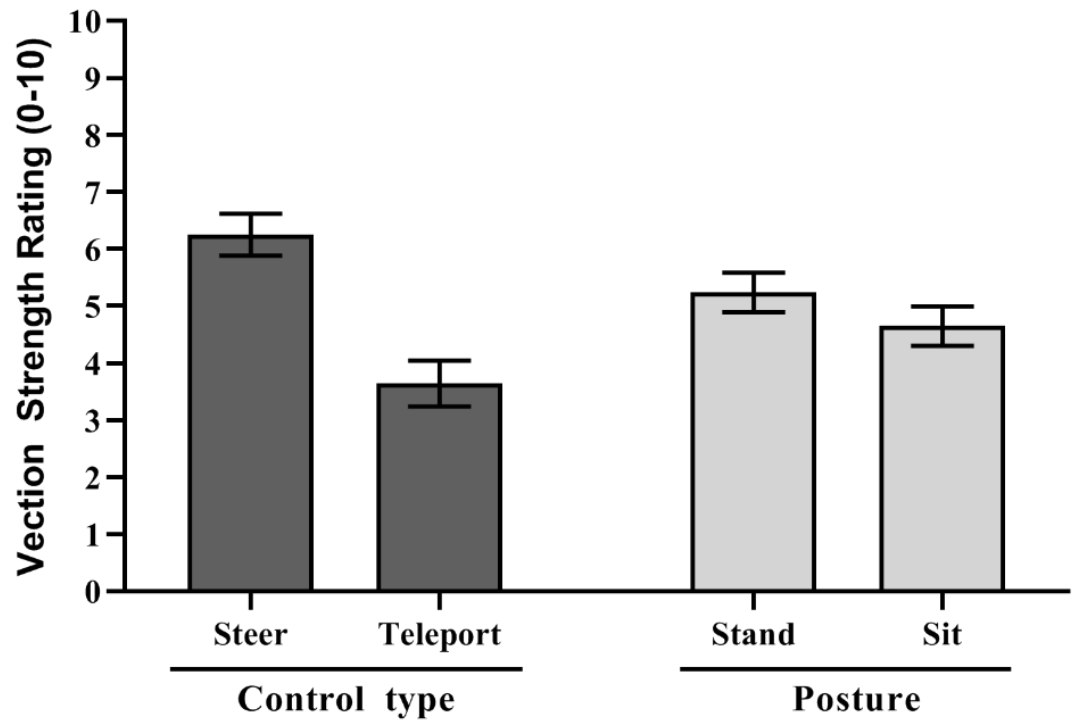

Fig 7. Mean vection strength ratings as a function of CONTROL TYPE and POSTURE. Error bars represent the standard error of the mean.

\subsection{Correlations between Cybersickness, Presence and Vection}

Regression and correlation models both assume that each data point is derived from a different participant (Lorch and Myers, 1990). However, as this experiment had a repeated measures design its data did not represent independent samples. Thus, in order to investigate possible relationships between the cybersickness, presence, and vection strength ratings in this study, we did the following: 1) for each participant, the peak FMS and verbal presence scores were extracted for each condition and then correlated with the overall vection strength ratings for those conditions; 2) the individual linear regression coefficients of FMS x Presence, FMS $x$ vection, and Presence $x$ vection were computed for each participant; and 3) one sample $t$-tests were conducted on these regression coefficient data to see if they differed significantly from zero. Results revealed that the relationship between vection and cybersickness was significant, $t(24)=2.551, p=.018, d=.510$. However, the relationships between presence and cybersickness, $t(24)=-.008, p=.993, d=.002$, and between vection and presence, $t(24)=1.735, p=.096, d=.347$, were not significant. This analysis demonstrates that there was a significant positive correlation between vection and cybersickness in the current study.

\section{DISCUSSION}

This study investigated two common methods of virtual locomotion used in VR (teleporting and steering locomotion). Its aim was to determine their effects on user experience and provide insights on how to maximize presence whilst minimizing the occurrence of cybersickness. Of the two virtual locomotion methods, teleportation was found on average to produce less cybersickness than steering locomotion. However, it should be noted that this did not reflect a general advantage for teleportation in terms of cybersickness. On closer inspection, we found that 9 of our 25 participants actually reported greater cybersickness when continuously teleporting (referred to as "TELEsick" as opposed to "STEERsick"). Interestingly, we found that these TELEsick and STEERsick participants appeared to display different patterns of spontaneous postural instability before they entered VR.

We also found differences in the feelings of presence generated in steering locomotion and teleporting trials. Steering locomotion was found to produce greater spatial presence and experienced realism than teleporting. For females (but not males) steering locomotion also produced greater overall ratings of presence than teleporting. Interestingly, these overall presence ratings were also found to increase over time during steering locomotion (but not teleporting) trials. 


\subsection{Cybersickness Incidence, Symptoms and Severity}

Cybersickness in this study appeared to be consistent with that found in past studies on HMD-based VR, in that the primary symptom was disorientation (see Rebinitsch and Owen 2016 for a recent review). However, it is noteworthy that oculomotor symptoms were scored higher than nausea symptoms in the current study (as the opposite pattern is often found during HMD-based VR). Importantly, the incidence of reported cybersickness was high - with $96 \%$ of our participants reporting that they felt sick on at least one of the four experimental trials (i.e., only one participant remained well for all four trials). The reported severity of this cybersickness was also higher than in recent studies (with the average peak FMS scores being 6.28 out of 20 compared to 3 out of 20 or lower in Palmisano and Riecke 2018 and Keshavarz et al. 2018). As expected, cybersickness severity also increased with the VR exposure duration (Ruddle 2004). These observations suggest that our experiment was more provocative for cybersickness than many previous studies. It should be noted however that Nature Treks VR is rated by Oculus as "comfortable" (as opposed to "moderate" or "intense"; there are similar anecdotal reports on Viveport and Steam). We strongly agree with this comfort rating based on our own free gameplay. The unexpectedly high rates and severity of cybersickness in the current experiment were most likely the result of our requirement that participants had to be continuously moving or teleporting for the majority of their VR exposures.

\subsection{Testing Theories of Cybersickness}

The two most popular theories of cybersickness had somewhat different predictions about the effectiveness of steering locomotion and teleporting in this study. Consistent with the general predictions of most sensory conflict theories, we found: 1) that steering locomotion generated greater cybersickness on average than teleporting; 2) that steering locomotion induced significantly stronger vection (illusory self-motion) than teleporting; and 3) a significant positive correlation between cybersickness and vection. As noted in the introduction, steering locomotion would be expected to generate more visual-vestibular conflict than teleporting, because it presents the physically stationary user with global optical flow (whereas the teleporting conditions do not) ${ }^{2}$. However, these findings, and their support for sensory conflict theories of cybersickness, are complicated by our observation that a significant subset of participants reported feeling sicker during teleporting than steering locomotion. The existence of "TELEsick", as well as "STEERsick", participants demonstrates that individuals can vary markedly in how they respond to different locomotion techniques. These two groups of participants would appear to be difficult to explain based on sensory conflict theories alone. However, it is conceivable that the participants in these groups might have differed either in their relative sensitivity to, or their neural weightings assigned to, visual and vestibular information.

Postural instability theory on the other hand predicts that participants who are more naturally unstable (i.e., before donning the HMD) will be more likely to experience cybersickness. While many past studies support this particular prediction, we were unable to test it with the data obtained in the current study. Due to the high incidence of cybersickness only one of our participants was classified as being well (with the remaining 24 participants classified as sick). Thus, we did not have sufficient numbers to determine whether sick and well participants differed based on their natural postural stability/activity. We did however examine another (potentially weaker) prediction of the theory, that sitting might reduce the severity of cybersickness compared to standing (this assumes that the additional support provided by the chair would reduce the user's postural instability during gameplay). Contrary to this prediction, and the findings of previous research by Merhi et al. (2007), sitting conditions did not produce significantly different cybersickness severity ratings to standing conditions. However, it should be noted that postural instability of the head or torso could still have contributed to cybersickness in the seated observers (Stoffregen et al. 2013; Villard et al. 2008). As the participants were still free to move their head and upper-bodies, and measurements of postural activity were not taken during VR gameplay, we concede that this may not have been a fair test of postural instability theory. Future research examining postural activity during virtual reality is therefore required to strongly test the influence of postural activity on HMD-based cybersickness. Thus, the strongest support for postural instability theory in this study appears to be the finding that "TELEsick" and "STEERsick" participants differed in their spontaneous postural activity (prior to donning the HMD). Specifically, our "TELEsick"

\footnotetext{
${ }^{2}$ Although it is commonly assumed that teleporting reduces sensory conflict, it is possible that some users experience expectancy violations due to the lack of visual and non-visual sensory information about their simulated self-displacement.
} 
participants were found to have significantly larger standard deviations in their CoP along the medio/lateral (M/L) axis (compared to the "STEERsick" participants).

Thus, it is possible that the overall effects of locomotor control on cybersickness in this study might be explained by combining both theories, with: 1) sensory conflict explaining the higher average cybersickness severity for steering locomotion and the overall relationship between cybersickness and vection, and 2) postural instability theory explaining the individual differences in sickness responses to the two types of locomotor control (based on the user's own natural degree of postural stability).

\subsection{Sex and Cybersickness}

Contrary to predictions, cybersickness did not appear to differ between the male and female participants in our current study. The incidence of cybersickness was high for both sexes, and we found no significant differences in the severity of their symptoms. While there are a growing number of studies reporting that females might be more susceptible to motion sickness/cybersickness than males (Allen et al. 2016; De Leo et al. 2014; Garcia et al. 2010; Koslucher et al. 2015; Lawther and Griffin 1988; Merhi et al. 2007; Munafo et al. 2017; Read and Bohr 2014), several recent studies have produced null findings (Al Zayer et al. 2019; Arcioni et al. 2018; Llorach et al. 2014). A number of studies have also found that women were more likely to report being sick (as opposed to well), even when the sick men and sick women in them did not appear to differ in terms of sickness severity (e.g., Munafo et al. 2017; Koslucher et al. 2015). The failure of the current study to find sex-based differences in cybersickness could also have been due to the particularly provocative experimental conditions that we appear to have used (which might have masked sex-based differences in susceptibility to less provocative stimuli/conditions). Recent research has also suggested that video game experience can increase users' tolerance to cybersickness during VR locomotion (Sargunam et al. 2017). As males are generally more likely to have greater video game experience ${ }^{3}$, this overlap should be considered in future investigations of sex differences in cybersickness.

\subsection{Effects of Locomotion Control Type on Presence}

Aside from one study reporting that presence was improved during steering locomotion compared to teleporting (Vlahovic et al. 2018), the past research has largely failed to find differences in presence between control types (Bozgeyikli et al. 2016; Frommel et al. 2017; Habgood et al. 2018). However, in the current study, we observed several locomotion control type effects on presence, which are discussed in detail below.

First, we found that steering locomotion scored higher than teleporting on both the spatial presence and experienced realism sub-scores of the IPQ. The former finding is difficult to explain based on differences in vection, as we did not find a significant correlation between the vection and overall presence ratings obtained in this study. Instead, these IPQ subscale findings appear to be the result of the effects of teleporting and steering locomotion on the place and plausibility illusions respectively. While the place illusion is thought to improve with the degree of immersion (Slater 2009), the plausibility illusion is thought to be driven by the coherence of the VR simulation (Skarbez et al. 2017). Thus, it is likely that the blinks in the visual simulation during teleportation interrupted immersion, which in turn reduced the user's place illusion and their feelings of spatial presence (i.e., "being there" in the virtual environment). Similarly, it is also likely that teleportation was perceived to be a less coherent method of navigation than steering (particularly, given the way teleportation was used continuously in the current study). If teleporting conditions generated weaker plausibility illusions, this would explain why experienced realism was reduced for these trials (compared to the steering locomotion trials).

We also observed a novel interaction between sex and control type on verbal presence ratings made during exposure to HMD-based VR. Specifically, steering locomotion was found to produce higher ratings of presence than teleportation for our female, but not male, participants. Although sex-based differences in presence have been observed previously in the literature (males generally report greater presence and involvement than females Felnhofer et al. 2014; Felnhofer et al. 2012; Lachlan and Kremar 2011), we had not predicted that locomotion control effects on presence would differ based on biological sex. The sensitivity of self-report measures to task demands may have factored into these findings, and therefore objective, auxiliary indicators of presence are needed to

\footnotetext{
${ }^{3}$ In the current study we found that only two of our 12 female participants regularly played video games, compared to ten of our 13 male participants.
} 
confirm/validate these effects (as has been done in the vection literature - e.g., Kim \& Palmisano 2010; Palmisano et al. 2012, 2016; see Palmisano et al., 2015 for a review). Alternatively, it is possible that these results were simply due to the fact that more of the male participants in this study played video games regularly (compared to the female participants). These male participants might have been more accustomed to first-person simulations in dynamic games, and were thus subsequently less impressed by, and involved with, the current VR simulation. The female participants, on the other hand, might have been comparatively more engaged by the novel experience of slowpaced virtual navigation and more receptive to presence cues/interruptions.

\subsection{Effect of Posture on Presence}

We had predicted that being seated would reduce the user's feelings of presence (compared to standing - since one would typically walk at their normal eye-height, not ride or drive, through the environment simulated by Nature Treks VR). Consistent with this prediction, we found that seated conditions produced lower verbal presence ratings and experienced realism sub-scores than the standing conditions (although posture-based differences did not reach significance for the spatial presence and involvement sub-scores of the IPQ). These significant findings suggest that presence and experienced realism are both influenced by the plausibility of user's interactions with his/her virtual environment (Slater 2009; Skarbez et al. 2017). It is possible that these posture type effects could be explained by immersion rather than coherence (e.g., the somatosensory stimulation generated by sitting on the chair might have caused users to become more aware of their actual, physical surroundings). However, this appears unlikely since these effects were restricted to experienced realism, and did not generalize to spatial presence.

\subsection{Minimizing Cybersickness and Maximizing Presence}

Based on their recent review of the literature, Weech and colleagues (2019) concluded that the balance of evidence favors a negative relationship between presence and cybersickness. Contrary to this conclusion, the current study failed to find a significant relationship between presence and cybersickness during HMD-based VR. It should be noted that only a few of the studies reviewed by Weech et al. (2019) used HMD-based VR. As they themselves note, the findings of past studies were also quite mixed (e.g., Mania and Chalmers 2001, Seay et al. 2002 and Robillard et al. 2003 all produced null findings when searching for this possible relationship). Although we only had data from 25 participants in the current study, it is noteworthy that this was sufficient to observe a significant relationship between vection and cybersickness. Our results suggest that the cybersickness generated by HMDbased VR does not significantly inhibit the user's feelings of presence, potentially because HMD's can induce much stronger feelings of presence than other types of VR and simulation (Mondellini et al. 2018).

\subsection{Implications}

A standard virtual locomotion method that is received equally well by all users would be ideal for navigation in HMD-based VR (Steinicke et al. 2013). However, we found large individual differences in user responses to the two virtual navigation methods tested in this study. Teleporting did not reduce cybersickness in all of our users and steering locomotion appeared to have different effects on male and female ratings of presence. These findings suggest that it will be challenging to develop a universally favored navigation method for HMD-based VR. It may be that enabling realistic, comfortable virtual locomotion requires specific methods for different individuals and contexts. More research is required to identify what group-based/individual differences exist, and to clarify which groups and contexts will benefit most from each technique.

A major drawback to the widespread adoption of HMD-based VR is that even limited interactions can induce cybersickness in a significant proportion of people/users. On their own, neither sensory conflict, nor postural instability, theories appeared to be able to fully account for the incidence or severity of cybersickness in this study. However, the study findings coupled with those of previous research (Munafo et al. 2017; Arcioni et al. 2018) point to the practical utility of postural measurement in predicting cybersickness. It is possible that in the future a relatively cheap device, such as the Nintendo Wii Balance Board (Huurnink et al. 2013), could be used prior to (or during) VR exposure to customize application settings and reduce cybersickness. Also, given the predictive role of 
postural stability in cybersickness incidence, the provision of stable simulated reference frames may also assist in reducing cybersickness during virtual travel for unstable participants (see Cao et al. 2018; Nguyen-Vo et al. 2018).

While this study only examined postural activity prior to HMD-based gameplay, future studies are also needed to investigate postural activity during HMD-based gameplay. Studies have shown that decreases in postural stability precede the onset of sickness during exposure to physical scene motions and external motion displays. Indeed, studies suggest that postural activity during virtual/optical flow may be a more reliable predictor of motion sickness (compared to spontaneous postural instability before the exposure to any optic flow - see Cook et al., 2018; Smart et al., 2014). However, research is still needed to confirm that these changes in postural activity also occur just before the users' first reports of cybersickness during HMD-based VR.

\section{CONCLUSIONS}

This study has shown that controller-based locomotion techniques can have large and variable effects on cybersickness and presence within HMD-based VR. Our results suggest that teleportation is not a complete solution to the problem of cybersickness in VR as individuals vary significantly in their responses to this locomotion technique. Medio/lateral spontaneous postural instability appeared to be able to predict individual preferences for control types, although additional research is required to further elucidate the differences between "TELEsick" and "STEERsick" groups. We also found evidence that one cost of implementing teleportation for VR locomotion was a reduction in the feeling of presence. By contrast, steering locomotion was found to produce much more compelling presence, which generally increased with the user's time in VR. Although this may turn out to be a necessary expense for minimizing cybersickness, other methods of locomotion (possibly even alternative varieties of teleportation to the one presently discussed) which do not impact the experience of presence would be preferable.

\section{REFERENCES}

Al Zayer M, Adhanom IB, MacNeilage P, Folmer E (2019) The Effect of Field-of-View Restriction on Sex Bias in VR Sickness and Spatial Navigation Performance. CHI Conference on Human Factors in Computing Systems Proceedings 354. https://doi.org/10.1145/3290605.3300584

Allen B, Hanley T, Rokers B, Green CS (2016) Visual 3D motion acuity predicts discomfort in 3D stereoscopic environments. Entertainment Computing 13:1-9. https://doi.org/10.1016/j.entcom.2016.01.001

Arcioni B, Palmisano S, Apthorp D, Kim J (2018) Postural stability predicts the likelihood of cybersickness in active HMD-based virtual reality. Displays 58:3-11. https://doi.org/10.1016/j.displa.2018.07.001

Bangay S, Preston L (1998) An investigation into factors influencing immersion in interactive virtual reality environments. Studies in health technology and informatics:43-51. https://doi.org/ 10.1016/j.apergo.2016.05.003

Bhagat K, Wei-Kai L, Chun-Yen C (2016) A cost-effective interactive 3D virtual reality system applied to military live firing training. Virtual Reality 20:127-140. https://doi.org/10.1007/s10055-016-0284-x

Bles W, Bos JE, De Graaf B, Groen E, Wertheim AH (1998) Motion sickness: only one provocative conflict? Brain research bulletin 47:481-487. https://doi.org/10.1016/S0361-9230(98)00115-4

Boletsis C (2017) The New Era of Virtual Reality Locomotion: A Systematic Literature Review of Techniques and a Proposed Typology. Multimodal Technologies and Interaction 1:24. https://doi.org/10.3390/mti1040024

Bonato F, Bubka A, Alfieri L (2004) Display color affects motion sickness symptoms in an optokinetic drum. Aviation, space, and environmental medicine 75:306-311.

Bonato F, Bubka A, Palmisano S, Phillip D, Moreno G (2008) Vection Change Exacerbates Simulator Sickness in Virtual Environments. Presence: Teleoperators \& Virtual Environments 17:283-292. https://doi.org/10.1162/pres.17.3.283

Bonato F, Bubka A, Story M (2005) Rotation direction change hastens motion sickness onset in an optokinetic drum. Aviation, Space, and Environmental Medicine 76:823-827. 
Bonnet CT, Faugloire E, Riley MA, Bardy BG, Stoffregen TA (2006) Motion sickness preceded by unstable displacements of the center of pressure. Human Movement Science 25:800-820. https://doi.org/10.1016/j.humov.2006.03.001

Bouchard S, Robillard G, St-Jacques J. Dumoulin S, Patry MJ, Renaud P (2004) Reliability and validity of a singleitem measure of presence in VR. Proceedings of the $2^{\text {nd }}$ International Conference on Creating, Connecting and Collaborating through Computing:56-61. https://doi.org/10.1109/HAVE.2004.1391882

Bozgeyikli E, Raij A, Katkoori S, Dubey R (2016) Point \& teleport locomotion technique for virtual reality. Proceedings of the 2016 Annual Symposium on Computer-Human Interaction in Play:205-216. https://doi.org/10.1145/2967934.2968105

Bowman DA, Koller D, Hodges LF (1997) Travel in immersive virtual environments: An evaluation of viewpoint motion control techniques. Proceedings IEEE Annual International Symposium on Virtual Reality 1997:45-52. https://doi.org/10.1109/VRAIS.1997.583043

Busscher B, de Vliegher D, Ling Y, Brinkman WP (2011) Physiological measures and self-report to evaluate neutral virtual reality worlds. Journal of Cybertherapy and Rehabilitation 4:15-25.

Cao Z, Jerald J, Kopper R (2018). Visually-induced motion sickness reduction via static and dynamic rest frames. Proceedings IEEE Virtual Reality and 3D User Interfaces 2018:105-112 https://doi.org/10.1109/VR.2018.8446210

Chang CH, Pan WW, Tseng LY, Stoffregen TA (2012) Postural activity and motion sickness during video game play in children and adults. Experimental brain research 217:299-309. https://doi.org/10.1007/s00221-011-29934

Chang CH, PanWW, Chen FC, Stoffregen TA (2013) Console video games, postural activity, and motion sickness during passive restraint. Experimental brain research 229:235-242. https://doi.org/10.1007/s00221-013-3609-y

Christou CG, Aristidou P (2017) Steering versus teleport locomotion for head mounted displays. Proceedings International Conference on Augmented Reality, Virtual Reality and Computer Graphics 2017:431-446. https://doi.org/10.1007/978-3-319-60928-7_37

Cook HE, Hassebrock JA, Smart LJ (2018) Other People's Posture: Visually induced motion sickness from naturally generated optic flow. Frontiers in psychology 9:1901. https://doi.org/10.3389/fpsyg.2018.01901

Cooper N, Milella F, Cant I, Pinto C, White MD, Meyer GF (2016) The effects of multisensory cues on the sense of presence and task performance in a virtual reality environment. Perception 45:332-333.

Cummings JJ, Bailenson JN (2016) How Immersive Is Enough? A Meta-Analysis of the Effect of Immersive Technology on User Presence. Media Psychology 19:272-309. https://doi.org/10.1080/15213269.2015.1015740

De Leo G, Diggs LA, Radici E, Mastaglio TW (2014) Measuring sense of presence and user characteristics to predict effective training in an online simulated virtual environment. Simulation in Healthcare 9:1-6. https://doi.org/10.1097/SIH.0b013e3182a99dd9

Diels C, Ukai K, Howarth PA (2007) Visually induced motion sickness with radial displays: effects of gaze angle and fixation. Aviation, space, and environmental medicine 78:659-665.

Felnhofer A, Kothgassner OD, Beutl L, Hlavacs H, Kryspin-Exner I (2012) Is virtual reality made for men only? Exploring gender differences in the sense of presence. Proceedings of the International Society on presence research:103-12.

Felnhofer A, Kothgassner OD, Hauk N, Beutl L, Hlavacs H, Kryspin-Exner I (2014) Physical and social presence in collaborative virtual environments: Exploring age and gender differences with respect to empathy. Computers in Human Behaviour 31:272-9. https://doi.org/10.1016/j.chb.2013.10.045

Flanagan MB, May JG, Dobie TG (2002) Optokinetic nystagmus, vection, and motion sickness. Aviation, space, and environmental medicine 73:1067-1073.

Freitag S, Rausch D, Kuhlen T (2014) Reorientation in virtual environments using interactive portals. 2014 IEEE Symposium on 3D User Interfaces (3DUI):119-122. https://doi.org/10.1109/3DUI.2014.6798852

Frommel J, Sonntag S, Weber M (2017) Effects of controller-based locomotion on player experience in a virtual reality exploration game. Proceedings of the 12th International Conference on the Foundations of Digital Games:30-36. https://doi.org/10.1145/3102071.3102082

Gamito P, Oliveira J, Santos P, Morais D, Saraiva T, Pombal M, Mota B (2008) Presence, immersion and cybersickness assessment through a test anxiety virtual environment. Annual Review of CyberTherapy and Telemedicine 6:83-90. 
Garcia A, Baldwin C, Dworsky M (2010) Gender differences in simulator sickness in fixed-versus rotating-base driving simulator. Proceedings of the Human Factors and Ergonomics Society Annual Meeting 54:1551-1555. https://doi.org/10.1177/154193121005401941

Gavgani AM, Hodgson DM, Nalivaiko E (2017) Effects of visual flow direction on signs and symptoms of cybersickness. PLoS One 12. https://doi.org/10.1371/journal.pone.0182790

Golding JF, Doolan K, Acharya A, Tribak M, Gresty MA (2012) Cognitive cues and visually induced motion sickness. Aviation, space, and environmental medicine 83:477-482. https://doi.org/10.3357/ASEM.3095.2012

Habgood J, Moore D, Wilson D, Alapont S (2018) Rapid, continuous movement between nodes as an accessible virtual reality locomotion technique. Proceedings IEEE Virtual Reality 2018. https://doi.org/10.1109/VR.2018.8446130

Hill K, Howarth P (2000) Habituation to the side effects of immersion in a virtual environment. Displays, 21:25-30. https://doi.org/10.1016/S0141-9382(00)00029-9

Huurnink A, Fransz DP, Kingma I, van Dieën JH (2013) Comparison of a laboratory grade force platform with a Nintendo Wii Balance Board on measurement of postural control in single-leg stance balance tasks. Journal of biomechanics 46:1392-1395. https://doi.org/10.1016/j.jbiomech.2013.02.018

Ji JT, So RH, Cheung RT (2009) Isolating the effects of vection and optokinetic nystagmus on optokinetic rotationinduced motion sickness. Human factors 51:739-751. https://doi.org/10.1177/0018720809349708

Kennedy RS, Lane NE, Berbaum KS, Lilienthal MG (1993) Simulator sickness questionnaire: An enhanced method for quantifying simulator sickness. The international Journal of Aviation Psychology 3:203-220. https://doi.org/10.1207/s15327108ijap0303_3

Keshavarz B, Hecht H (2011) Validating an efficient method to quantify motion sickness. Human Factors 53:41526. https://doi.org/10.1177/0018720811403736

Keshavarz B, Hecht H, Lawson BD (2015) Visually induced motion sickness: Causes, characteristics, and countermeasures. In Hale KS, Stanney KM (Eds.) Handbook of Virtual Environments: Design, Implementation, and Applications. CRC Press, Florida: Boca Raton, pp. 647-689

Keshavarz B, Hettinger LJ, Vena D, Campos JL (2014) Combined effects of auditory and visual cues on the perception of vection. Exp. Brain Res. 232:827-836. https://doi.org/10.1007/s00221-013-3793-9

Keshavarz B, Novak AC, Hettinger LJ, Stoffregen TA, Campos JL (2017) Passive restraint reduces visually induced motion sickness in older adults. Journal of Experimental Psychology: Applied 23:85-99. https://doi.org/10.1037/xap0000107

Keshavarz B, Phillip-Muller AE, Hemmerich W, Riecke BE, Campos JL (2018) The effect of visual motion stimulus characteristics on vection and visually induced motion sickness. Displays 58:71-81. https://doi.org/10.1016/j.displa.2018.07.005

Kim YY, Kim HJ, Kim EN, Ko HD, Kim HT (2005) Characteristic changes in the physiological components of cybersickness. Psychophysiology 42:616-625. https://doi.org/10.1111/j.1469-8986.2005.00349.x

Kim J, Palmisano S (2010) Eccentric gaze dynamics enhance vection in depth. Journal of Vision 10(12):7. https://doi.org/10.1167/10.12.7

Knight MM, Arns LL (2006) The relationship among age and other factors on incidence of cybersickness in immersive environment users. Proceedings of the 3Rd Symposium: Applied Perception In Graphics \& Visualization 162. https://doi.org/10.1145/1140491.1140539

Koslucher F, Haaland E, Malsch A, Webeler J, Stoffregen TA (2015) Sex difference in the incidence of motion sickness induced by linear visual oscillation. Aerospace Medicine and Human Performance 86:787-793. https://doi.org/10.3357/AMHP.4243.2015

Koslucher F, Haaland E, Stoffregen TA (2016) Sex differences in visual performance and postural sway precede sex differences in visually induced motion sickness. Experimental Brain Research 234:313-322. https://doi.org/10.1007/s00221-015-4462-y

Lachlan K, Kremar M (2011) Experiencing presence in video games: The role of presence tendencies, game experience, gender, and time spent in play. Communication Research Reports 28:27-31. https://doi.org/10.1080/08824096.2010.518924

Lackner JR (2014) Motion sickness: More than nausea and vomiting. Experimental Brain Research 232:2493-2510. https://doi.org/10.1007/s00221-014-4008-8 
Langbehn E, Lubos P, Steinicke F (2018) Evaluation of Locomotion Techniques for Room-Scale VR. Joystick, Teleportation, and Redirected Walking. Proceedings of the Virtual Reality International Conference (VRIC). https://doi.org/10.1145/3234253.3234291

Lawson BD (2015) Motion sickness symptomatology and origins. In Hale KS, Stanney KM (Eds.), Handbook of Virtual Environments: Design, Implementation, and Applications. CRC Press, Florida: Boca Raton, pp. 532587.

Lawther A, Griffin MJ (1988) A survey of the occurrence of motion sickness amongst passengers at sea. Aviation, space, and environmental medicine 59:399-406. https://doi.org/10.1080/00140138808966783

Lin JW, Duh HBL, Parker DE, Abi-Rached H, Furness TA (2002) Effects of field of view on presence, enjoyment, memory, and simulator sickness in a virtual environment. Proceedings IEEE virtual reality 2002:164-171. https://doi.org/10.1109/VR.2002.996519

Ling Y, Nefs HT, Brinkman WP, Qu C, Heynderickx I (2013) The relationship between individual characteristics and experienced presence. Computers in Human Behavior 29:1519-1530. https://doi.org/10.1371/journal.pone.0096144

Ling Y, Nefs HT, Morina N, Heynderickx I, Brinkman WP (2014) A Meta-Analysis on the Relationship between Self-Reported Presence and Anxiety in Virtual Reality Exposure Therapy for Anxiety Disorders. PLoS One 9:112. https://doi.org/10.1371/journal.pone.0096144

Liu CL, Uang ST (2011) Effects of presence on causing cybersickness in the elderly within a 3D virtual store. International Conference on Human-Computer Interaction:490-499. https://doi.org/10.1007/978-3-642-216190_61

Liu X, Liu Y, Zhu X, An M, Hu F (2016) Virtual reality based navigation training for astronaut moving in a simulated space station. International Conference on Virtual, Augmented and Mixed Reality:416-423. https://doi.org/10.1007/978-3-319-39907-2_40

Llorach G, Evans A, Blat J (2014) Simulator sickness and presence using HMDs: comparing use of a game controller and a position estimate system. Proceedings of the 20th ACM Symposium on Virtual Reality Software and Technology:137-140. https://doi.org/10.1145/2671015.2671120

Lorch RF, Myers JL (1990) Regression analyses of repeated measures data in cognitive research. Journal of Experimental Psychology: Learning, Memory, and Cognition 16:149-157. https://doi.org/10.1037/02787393.16.1.149

Mania K, Chalmers A (2001) The effects of levels of immersion on memory and presence in virtual environments: A reality centered approach. CyberPsychology \& Behavior 4:247-264. https://doi.org/10.1089/109493101300117938

Merhi O, Faugloire E, Flanagan MB, Stoffregen TA (2007) Motion sickness, console video games, and headmounted displays. Human Factors: The Journal of the Human Factors and Ergonomics Society 49:920- 934. https://doi.org/10.1518/001872007X230262

Milleville-Pennel I, Charron C (2015) Do mental workload and presence experienced when driving a real car predispose drivers to simulator sickness? An exploratory study. Accident Analysis \& Prevention 74:192-202. https://doi.org/10.1016/j.aap.2014.10.021

Moghadam KR, Banigan C, Ragan ED (2018) Scene Transitions and Teleportation in Virtual Reality and the Implications for Spatial Awareness and Sickness. Proceedings IEEE transactions on visualization and computer graphics. https://doi.org/10.1109/TVCG.2018.2884468

Mondellini M, Arlati S, Greci L, Ferrigno G, Sacco M (2018) Sense of Presence and Cybersickness While Cycling in Virtual Environments: Their Contribution to Subjective Experience. In De Paolis L, Bourdot P (eds), Augmented Reality, Virtual Reality, and Computer Graphics. Springer, Cham, pp. 3-20. https://doi.org/10.1007/978-3-319-95270-3_1

Munafo J, Diedrick M, Stoffregen TA (2017) The virtual reality head-mounted display Oculus Rift induces motion sickness and is sexist in its effects. Experimental Brain Research 235:889-901. https://doi.org/10.1007/s00221016-4846-7

Nguyen-Vo T, Riecke BE, Stuerzlinger W (2018) Simulated reference frame: A cost-effective solution to improve spatial orientation in VR. Proceedings IEEE Virtual Reality and 3D User Interfaces 2018:415-422. https://doi.org/10.1109/VR.2018.8446383 
Nichols S, Haldane C, Wilson JR (2000) Measurement of presence and its consequences in virtual environments. International Journal of Human-Computer Studies 52:471-491. https://doi.org/10.1006/ijhc.1999.0343

Nooij SA, Pretto P, Oberfeld D, Hecht H, Bülthoff HH (2017) Vection is the main contributor to motion sickness induced by visual yaw rotation: Implications for conflict and eye movement theories. PLoS One 12. https://doi.org/10.1371/journal.pone.0175305

Oman CM (1982) A heuristic mathematical model for the dynamics of sensory conflict and motion sickness. Acta Oto-Laryngol 392:1-44.

Palmisano S, Allison RS, Schira MM, Barry RJ (2015) Future challenges for vection research: definitions, functional significance, measures, and neural bases. Frontiers in psychology 6:1-15. https://doi.org/10.3389/fpsyg.2015.00193

Palmisano S, Arcioni B, Stapley PJ (2017a) Predicting vection and visually induced motion sickness based on spontaneous postural activity. Experimental Brain Research 236:315-329. https://doi.org/10.1007/s00221-017$5130-1$

Palmisano S, Barry RJ, De Blasio FM, Fogarty JS (2016) Identifying objective EEG based markers of linear vection in depth. Frontiers in Psychology 7:1205. https://doi.org/10.3389/fpsyg.2016.01205

Palmisano S, Kim J, Allison R, Bonato F (2011) Simulated viewpoint jitter shakes sensory conflict accounts of vection. Seeing and perceiving 24:173-200. https://doi.org/10.1163/187847511X570817

Palmisano S, Kim J, Freeman TCA (2012) Horizontal fixation point oscillation and simulated viewpoint oscillation both increase vection in depth. Journal of Vision, 12(12):15. https://doi.org/10.1167/12.12.15

Palmisano S, Mursic R, Kim J (2017b) Vection and cybersickness generated by head-and-display motion in the Oculus Rift. Displays 46:1-8. https://doi.org/10.016/j.displa.2016.11.001

Palmisano S, Riecke BE (2018) The search for instantaneous vection: An oscillating visual prime reduces vection onset latency. PLoS One 13. https://doi.org/10.1371/journal.pone.0195886

Palmisano SA, Bonato F, Bubka A, Folder J (2007) Vertical display oscillation effects on forward vection and simulator sickness. Aviation, Space, and Environmental Medicine 78:951-956. https://doi.org/10.3357/ASEM.2079.2007

Pedram S, Perez P, Palmisano S, Farrelly M (2018) The Factors Affecting the Quality of Learning Process and Outcome in Virtual Reality Environment for Safety Training in the Context of Mining Industry. International Conference on Applied Human Factors and Ergonomics 2018:404-411. https://doi.org/10.1007/978-3-31994223-0_38

Ragan ED, Wood A, McMahan RP, Bowman DA (2012) Trade-Offs Related to Travel Techniques and Level of Display Fidelity in Virtual Data-Analysis Environments. Proceedings Joint Virtual Reality conference of ICAT/EGVE/EuroVR 2012:81-84.

Read JA, Bohr I (2014) User experience while viewing stereoscopic 3D television. Ergonomics 57:1140-1153. https://doi.org/10.1080/00140139.2014.914581

Reason JT, Brand JJ (1975) Motion Sickness. Academic Press, New York.

Rebenitsch L, Owen C (2016) Review on cybersickness in applications and visual displays. Virtual Reality 20:101125. https://doi.org/10.1007/s10055-016-0285-9

Riccio GE, Stoffregen TA (1991) An ecological theory of motion sickness and postural instability. Ecological Psychology 3:195-240. https://doi.org/10.1207/s15326969eco0303_2

Riecke BE, Jordan JD (2015) Comparing the effectiveness of different displays in enhancing illusions of selfmovement (vection). Frontiers in psychology 6:713. https://doi.org/10.3389/fpsyg.2015.00713

Riecke BE, Schulte-Pelkum J, Avraamides MN, Heyde MVD, Bülthoff HH (2006) Cognitive factors can influence self-motion perception (vection) in virtual reality. ACM Transactions on Applied Perception (TAP) 3:194-216. https://doi.org/10.1145/1166087.1166091

Robillard G, Bouchard S, Fournier T, Renaud P (2003) Anxiety and presence during VR immersion: A comparative study of the reactions of phobic and non-phobic participants in therapeutic virtual environments derived from computer games. CyberPsychology \& Behavior 6:467-476. https://doi.org/10.1089/109493103769710497

Rothbaum BO, Price M, Jovanovic T, Norrholm SD, Gerardi M, Dunlop B et al (2014) A randomized, double-blind evaluation of D-cycloserine or alprazolam combined with virtual reality exposure therapy for posttraumatic stress disorder in Iraq and Afghanistan War veterans. American Journal of Psychiatry 171:640-648. https://doi.org/10.1176/appi.ajp.2014.13121625 
Ruddle RA (2004) The effect of environment characteristics and user interaction on levels of virtual environment sickness. Proceedings IEEE Virtual Reality 2004:141. https://doi.org/10.1109/VR.2004.13

Ruddle RA, Volkova E, Bülthoff HH (2011) Walking improves your cognitive map in environments that are largescale and large in extent. ACM Transactions on Computer-Human Interaction (TOCHI) 18:10. https://doi.org/10.1145/1970378.1970384

Sargunam SP, Moghadam KR, Suhail M, Ragan ED (2017) Guided head rotation and amplified head rotation: Evaluating semi-natural travel and viewing techniques in virtual reality. Proceedings IEEE Virtual Reality 2017:19-28. https://doi.org/10.1109/VR.2017.7892227

Schubert T, Friedmann F, Regenbrecht H (2001) The experience of presence: Factor analytic insights. Presence: Teleoperators \& Virtual Environments 10:266-281. https://doi.org/10.1162/105474601300343603

Seay AF, Krum DM, Hodges L, Ribarsky W (2002) Simulator sickness and presence in a high field-of-view virtual environment. CHI'02 Extended Abstracts on Human Factors in Computing Systems:784-785. https://doi.org/10.1145/506443.506596

Skarbez R, Brooks FJ, Whitton MC (2017) A Survey of Presence and Related Concepts. ACM Computing Surveys 50:96. https://doi.org/10.1145/3134301

Slater M (2009) Place illusion and plausibility can lead to realistic behaviour in immersive virtual environments. Philosophical Transactions of the Royal Society B: Biological Sciences 364:3549-3557. https://doi.org/10.1098/rstb.2009.0138

Slater M, Steed A (2000) A virtual presence counter. Presence: Teleoperators and Virtual Environments 9:413-434. https://doi.org/10.1162/105474600566925

Slater M, Wilbur S (1997) A framework for immersive virtual environments (FIVE): Speculations on the role of presence in virtual environments. Presence: Teleoperators \& Virtual Environments 6:603-616. https://doi.org/10.1162/pres.1997.6.6.603

Smart LJ, Otten EW, Strang AJ, Littman EM, Cook HE (2014) Influence of complexity and coupling of optic flow on visually induced motion sickness. Ecological Psychology 26(4):301-324. https://doi.org/10.1080/10407413.2014.958029

Smart LJ, Stoffregen TA, Bardy BG (2002) Visually induced motion sickness predicted by postural instability. Human Factors: The Journal of the Human Factors and Ergonomics Society 44:451-465. https://doi.org/10.1518/0018720024497745

Souman JL, Giordano PR, Schwaiger M, Frissen I, Thümmel T, Ulbrich H, De Luca A, Bülthoff HH, Ernst MO (2011) CyberWalk: Enabling unconstrained omnidirectional walking through virtual environments. ACM Transactions on Applied Perception 8:25. https://doi.org/10145/2043603.2043607

Steinicke F, Visell Y, Campos JL, Lécuyer A (2013) Human walking in virtual environments: Perception, technology, and applications. Springer, Verlag.

Stoffregen TA, Chen FC, Varlet M, Alcantara C, Bardy BG (2013) Getting your sea legs. PLoS One 8. https://doi.org/10.1371/journal.pone.0066949

Stoffregen TA, Chen YC, Koslucher FC (2014) Motion control, motion sickness, and the postural dynamics of mobile devices. Experimental brain research 232:1389-1397. https://doiorg.ezproxy.uow.edu.au/10.1007/s00221-014-3859-3

Stoffregen TA, Faugloire E, Yoshida K, Flanagan MB, Merhi O (2008) Motion sickness and postural sway in console video games. Human factors 50:322-331. https://doi.org/10.1518/001872008X250755

Stoffregen TA, Hettinger LJ, Haas MW, Roe MM, Smart LJ (2000) Postural instability and motion sickness in a fixed-base flight simulator. Human Factors 42:458-469. https://doi.org/10.1518/001872000779698097

Stoffregen TA, Smart LJ (1998) Postural instability precedes motion sickness. Brain Research Bulletin 47:437-448. https://doi.org/10.1016/S0361-9230(98)00102-6

Stoffregen TA, Yoshida K, Villard S, Scibora L, Bardy BG (2010) Stance width influences postural stability and motion sickness. Ecological Psychology 22:169-191. https://doi.org/10.1080/10407413.2010.496645

Villard SJ, Flanagan MB, Albanese GM, Stoffregen TA (2008) Postural instability and motion sickness in a virtual moving room. Human factors 50:332-345. https://doi.org/10.1518/001872008X250728

Vlahović S, Suznjevic M, Skorin-Kapov L (2018) Subjective Assessment of Different Locomotion Techniques in Virtual Reality Environments. 2018 Tenth International Conference on Quality of Multimedia Experience:1-3. https://doi.org/10.1109/QoMEX.2018.8463433 
Webb NA, Griffin MJ (2003) Eye movement, vection, and motion sickness with foveal and peripheral vision. Aviation, space, and environmental medicine 74:622-625.

Weech S, Kenny S, Barnett-Cowan M (2019) Presence and cybersickness in virtual reality are negatively related: a review. Frontiers in psychology 10:158. https://doi.org/10.3389/fpsyg.2019.00158

Weech S, Moon J, Troje NF (2018) Influence of bone-conducted vibration on simulator sickness in virtual reality. PLoS One 13. https://doi.org/10.1371/journal.pone.0194137

Wilson JR, Nichols S, Haldane C (1997) Presence and side effects: Complementary or contradictory? Advances in human factors/ergonomics: 889-892.

Witmer BG, Bailey JH, Knerr BW, Parsons KC (1996) Virtual spaces and real world places: transfer of route knowledge. International journal of human-computer studies 45:413-428. https://doi.org/10.1006/ijhc. 1996.0060

Witmer BG, Singer MJ (1998) Measuring presence in virtual environments: A presence questionnaire. Presence: Teleoperators and Virtual Environments 7:225-240. https://doi.org/10.1162/105474698565686

Yokota Y, Aoki M, Mizuta K, Ito Y, Isu N (2005) Motion sickness susceptibility associated with visually induced postural instability and cardiac autonomic responses in healthy subjects. Acta oto-laryngologica 125:280-285. https://doi.org/10.1080/00016480510003192

Zacharias GL, Young LR (1981) Influence of combined visual and vestibular cues on human perception and control of horizontal rotation. Experimental brain research 41:159-171. https://doi.org/10.1007/BF00236605 